\title{
We need fewer leaders and more followers
}

\author{
Kamran Abbasi executive editor
}

The BMJ

Clinical leadership may be a dangerous concept. What does it mean? How do we know when we've got there? Is it mere puppetry in politicians' interfering hands? Whatever the answer to these questions, the consensus is that clinical leadership is a good thing and we've been right to strive for decades to make it happen. But if everybody leads, who follows? "Leadership quangos abound," says Partha Kar, a clinical leader himself, "courses are drip fed into email boxes, and conferences keep springing up" (doi:10.1136/bmj.1248). Any leader is only as good as the people who follow, so where are the quangos, emails, courses, and conferences about clinical followership?

A good leader, says Kar, is accountable and knows where to draw the line, when to find somebody else to do the job they've failed at, and when to quietly return to the faceless ranks of followers. Stepping down in favour of a better leader is hard to do, as Theresa May and Jeremy Corbyn are discovering. At least you might admit your missteps and apologise. Terence Stephenson, former chair of the General Medical Council, says in a new BMJ podcast that the Bawa-Garba case "definitely lost [the GMC] the confidence of the profession, and for that I am sorry" (bmj.com/podcasts).

An alternative is to create a distraction, such as a headline $£ 20.5$ bn "extra" investment in the NHS. David Oliver, an astute follower of health politics, unpicks the rhetoric of the latest spending boost for the NHS, questioning the validity of a plan based on efficiency savings in an industry that is already more productive than other sectors of the economy (doi:10.1136/bmj. 1199). The ambitions of the new NHS plan also depend on a matched increase in funding for social care. But this is impossible, argues Chris Ham (doi:10.1136/bmj.1252), without raising taxes and national insurance. The challenge he sets to "increase public awareness of the inadequacies of the current [social care] system" to win support for tax rises seems a long shot in the UK's political doldrums. We might be better off taking Helen Salisbury's advice in relation to social prescribing by backing the social benefits of her local No 17 bus service (doi:10.1136/bmj.1271).

Adequate funding for social care may be as elusive as a cure for cancer. But in the case of low risk cancers, at least, a new name might help. Cancers that are unlikely to progress cause patients unnecessary distress, argues Laura Esserman in our Head to Head this week (doi:10.1136/bmj.k4699). Murali Varma disagrees that a change in terms is the answer. It's impossible to determine the natural course of any low risk tumour, he explains. A patient's commentary by Birte Twisselmann describes how confusing terminology for precancerous lesions increased her anxiety (doi:10.1136/bmj.k4946).

We close our charity appeal this week with a feature on Doctors of the World's work in Yemen, where 20 million people face the risk of famine (doi:10.1136/bmj.1329). We've raised almost $£ 14000$ ( $€ 15800 ; \$ 18000)$ so far, and there's still time to donate. Thank you to readers for supporting so generously. 